\title{
NDD. 07. Behavioral and antioxidant effects of Levetiracetam in a rat model of Parkinson's disease induced by 6-OHDA
}

\author{
AGUIAR, L.M.V. ${ }^{A}$, NORONHA, E.C ${ }^{A}$, BEZERRA, M.MP , FILHO, G.C ${ }^{A}$, SOUSA, F.C.F . \\ aMedicine Faculty, Federal University of Ceará - Sobral/Ce - Brazil; \\ b Department of Physiology and Pharmacology, Federal University of Ceará, Fortaleza - Ce \\ - Brazil.
}

Introduction: Parkinson's disease (PD) is a neurodegenerative disorder characterized by progressive destruction of the nigrostriatal dopaminergic neurons. The origin of this neuronal degeneration is unknown and probably involves many events including oxidative stress, inflammation, excitotoxicity and apoptosis. Current treatment consists of symptomatic relief, since there are no agents capable of inhibiting neuronal degeneration. Studies have shown that levetiracetam has an antioxidant, anti-inflammatory and antiapoptotic action, that may be correlated with possible neuroprotective effects in neurodegenerative diseases. This work aims to study the effects of levetiracetam (LEV) in an animal model of Parkinson's disease induced by intrastriatal injection of 6-OHDA by stereotactic surgery. Methods: Male Wistar rats (200-250g) were treated with LEV (50 and $100 \mathrm{mg} / \mathrm{kg}$, po) or saline starting 1 hour after the lesion and daily thereafter for 14 days. On the 15th day after surgery the animals were submitted to behavioral tests and then the animals were sacrificed and the brain areas were used for determination of nitrite levels. Results: LEV (LEV 50: $100.6 \pm 40.47$ (14); LEV 100 (2.23 \pm 0.84 (13)) produced a partial motor recovery by reducing the number of rotations when compared to injured control group (6 - OHDA: 265.9, $39.8 \pm(11))$. There was an improvement in locomotor activity in animals treated with LEV evidenced by the reduction of immobility time in the open field test (100 LEV: $93.00 \pm 10.97$ (4)) when compared to controls (6-OHDA: $195.0 \pm 20.63$ (7)). 6-OHDA caused an increase in the nitrite content (6-OHDA: $0.334 \pm 0.0389(5))$ which was reduced after treatment with LEV (LEV-50: $0.085 \pm 0.012$ (5)). Conclusions: The present study showed that the LEV partially reversed the behavioral changes and oxidative stress induced by 6-OHDA, with possibly neuroprotective effects in PD.

Keywords: levetiracetam; 6-hydroxydopamine; antioxidant

Funding: CNPq.

AGUIAR, L.M.V.; NORONHA, E.C.; BEZERRA, M.M.; FILHO, G.C.; SOUSA, F.C.F. 2013. Behavioral and antioxidant effects of Levetiracetam in a rat model of Parkinson's disease induced by 6-OHDA, p.36. In: Oriá, Reinaldo Barreto; Andrade, Geanne Matos de; Bruin, Veralice Meireles S. de. I International Symposium in Neuroscience Meeting [Blucher Neuroscience Proceedings n.1 v.1]. São Paulo: Blucher, 2014 http://dx.doi.org/10.5151/isnm-sine31

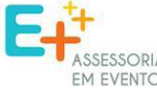

